\title{
Urgences
}

\section{Rocaille : octobre}

\section{Paul Chanel Malenfant et Harold Smyth}

Numéro 16, mars 1987

D.G. Jones : d'un texte, d'autres

URI : https://id.erudit.org/iderudit/025398ar

DOI : https://doi.org/10.7202/025398ar

Aller au sommaire du numéro

Éditeur(s)

Urgences

ISSN

0226-9554 (imprimé)

1927-3924 (numérique)

Découvrir la revue

Citer ce document

Malenfant, P. C. \& Smyth, H. (1987). Rocaille : octobre. Urgences, (16), 70-71.

https://doi.org/10.7202/025398ar d'utilisation que vous pouvez consulter en ligne.

https://apropos.erudit.org/fr/usagers/politique-dutilisation/ 


\section{Paul Chanel Malenfant/Harold Smyth ROCAILLE: OCTOBRE}

Et sous la pluie, la ruine

des ombres et

des tombeaux de pluie

aussi des fleurs, à flots

et des couleurs de feuilles.

Tombes. Les pierres fleurissent

comme des nombres comme

des livres où les morts

à toutes lèvres, parlent.

De plus en plus ma bouche est remplie de cailloux et les mots de mon père

ressemblent à des rocs fleuris

Est-ce pas perdus ou

Pointe-au-Père

ou cette ville de mer à l'heure

de l'ombre? de la mort

vivante elle passe

sombre, sous la pluie. Elle, avec des signes et des cailles et toute la tombée de l'eau. 
Soit: d'un texte qui dès son erre d'aller se ruine en rythmes, en rimes, en $r$. «Rock Garden: October»: «In the rain, it is a ruin...» Aux «motsflots» sont substitués les "mots-pierres». Fasciné, je ne parviens pas à résister à l'autorité lapidaire du poème de D.G. Jones. Poème paternel. (Où la mort même du père serait remémorée comme un "événement d'octobre»?) Je répète "More and more my mouth» et cela fait un courant d'air (froid) entre les lèvres. Étranger, le lecteur en perd le souffle comme s'il ne parvenait pas à respirer avec la voix de ce poème-là: «[...] qui n'est pas à moi/[poème] à moi que je ne puis pas prendre». Seule issue: ce lecteur retrouve et tourne la langue dite maternelle, alors que la poésie reste enclose en cette langue seconde (pourtant première au texte) qui est bien la seule diction légitime du poème. La traduction donc, comme transfert de l'interdit, l'impossible ravissement des mots dans la bouche de l'autre. Auteur.

Angles et mires: puisqu'il s'agit de lui, du père, je conserve les lieux où il se mire, comme la pluie, la ruine... Je lis des chiffres sur la pierre tombale, j'effeuille la bibliothèque, trace des petits vers cassés, graffiti anonymes. Là où, par inadvertance parfois, ça parle. Remontrances des épitaphes. - «Tourne ta langue dans la bouche», - «Pas un mot plus haut que l'autre». Transcrit (non traduit), mon poème (un faux papier) parle à voix basse, il insinue, lance des pointes - comme on dirait, justement, de l'ironie d'un trait. Aussi, du travail des miroirs. De l'énergie de «Rock Garden: October», je ne parviens à rendre que le lavis d'une fictive petite ville d'eau. Lagune maternelle. Traduire: état de deuil et de fadeur, car je sais bien que le poème que je tente en vain d'autrement dire, n'adviendra jamais dans le pareil et le même. Stade du miroir. Imaginaire et terrain vague. Ainsi, par exemple, il n'y a pas de sang dans le poème de D.G. Jones. En échange, je trouve ces curieux oiseaux, à la chute de mon texte à moi, tombés, fondus en eau. Vraiment: «les mots comme des caillots dans ta bouche...»Voilà donc une toute autre histoire et la salive sous le filet de la langue, ne parvient qu'à murmurer: "In the rain, it is a ruin..." 